\section{The Tyranny of Content: "Content Coverage" as a Barrier to Evidence-Based Teaching Approaches and Ways to Overcome It}

\author{
Christina I. Petersen, ${ }^{* *}$ Paul Baepler, ${ }^{\dagger}$ Al Beitz, ${ }^{\ddagger}$ Paul Ching, ${ }^{\S}$ Kristen S. Gorman, ${ }^{\dagger}$ \\ Cheryl L. Neudauer," William Rozaitis, ${ }^{+}$J. D. Walker, ${ }^{\dagger}$ and Deb Wingert ${ }^{\dagger}$ \\ ${ }^{\dagger}$ Center for Educational Innovation, University of Minnesota, Minneapolis, MN 55414; ‘Department \\ of Veterinary and Biomedical Sciences and Center for Educational Innovation, University of \\ Minnesota, Minneapolis, MN 55414; ' Graduate School, University of Minnesota, Twin Cities, \\ Minneapolis, MN 55455; ${ }^{\circledR B i o l o g y}$ Department, Minneapolis College, Minneapolis, MN 55403
}

\begin{abstract}
Instructors have inherited a model for conscientious instruction that suggests they must cover all the material outlined in their syllabus, and yet this model frequently diverts time away from allowing students to engage meaningfully with the content during class. We outline the historical forces that may have conditioned this teacher-centered model as well as the disciplinary pressures that inadvertently reward it. As a way to guide course revision and move to a learner-centered teaching approach, we propose three evidence-based strategies that instructors can adopt: 1) identify the core concepts and competencies for your course; 2 ) create an organizing framework for the core concepts and competencies; and 3) teach students how to learn in your discipline. We further outline examples of actions that instructors can incorporate to implement each of these strategies. We propose that moving from a content-coverage approach to these learner-centered strategies will help students better learn and retain information and apply it to new situations.
\end{abstract}

\section{INTRODUCTION}

Instructors in every field want to help their students comprehend the central tenets of their disciplines. A major challenge of pedagogy is how to help students acquire the knowledge, understanding, skills, and habits of mind that are characteristic of a field of study. The most traditional approach is through lecture, a method originally devised by medieval universities to communicate written content before the printing press was invented (Friesen, 2011). Such guided instruction was seen as an efficient way to organize and deliver pertinent information. Although today's lectures have evolved beyond continuous exposition to include some allowance for students' questions and for visual enhancement through the use of multimedia components, they have been primarily driven and limited by the need to deliver content to students. Many instructors conceive of delivering or covering content as one of their primary responsibilities. Barr and Tagg (1995) noted this phenomenon more than 20 years ago and identified it as an unintended product of a misplaced sense of duty: "Under the Instruction Paradigm," which continues to be persistent today, "the teacher's job is to "cover the material' as outlined in the disciplinary syllabus" (pp. 19-20).

The coverage metaphor (that teaching primarily entails presenting information on a series of topics) is aligned with a historical description of what it means to be a teacher. It is a powerful, lasting idea that can be difficult to surmount and even to frame as a problematic issue. This is the "tyranny of content," or the perception that covering content must take precedence in undergraduate courses. We use the term "content" to refer to all of the material-often in the form of facts-that students are
C. Gary Reiness, Monitoring Editor Submitted Apr 29, 2019; Revised Feb 20, 2020; Accepted Feb 27, 2020

CBE Life Sci Educ June 1, 2020 19:ar17 DOI:10.1187/cbe.19-04-0079

*Address correspondence to: Christina I. Petersen (pete6647@umn.edu)

(c) 2020 C. I. Petersen et al. CBE-Life Sciences Education () 2020 The American Society for Cell Biology. This article is distributed by The American Society for Cell Biology under license from the author(s). It is available to the public under an Attribution-Noncommercial-Share Alike 3.0 Unported Creative Commons License (http://creativecommons.org/licenses/ by-nc-sa/3.0).

"ASCB®" and "The American Society for Cell Biology $\circledR^{\prime}$ are registered trademarks of The American Society for Cell Biology. 
responsible for learning and mastery of which may be assessed. When we refer to "coverage," we mean all the mechanisms of presenting content to students through lectures, slides, readings, videos, and so on. The main impetus for this paper is the idea that the drive to "cover content" presents a formidable barrier to incorporating more learner-centered practices into undergraduate courses in general and into science and biology courses in particular. We will provide an account of where the imperative to cover content comes from and why it is so persistent. Building on this account, we will suggest strategies, informed by higher education pedagogical research literature and our experience as faculty teaching consultants and instructors, for helping instructors move beyond the need to cover content and toward an alternative vision of what good teaching is.

\section{Background}

During the past few decades, the traditional lecture has come under increasing criticism as mounting evidence has confirmed that most students learn better by engaging with content and reflecting upon it, a method commonly referred to as "active learning" (Hake, 1998; Prince, 2004; Knight and Wood, 2005; Handelsman et al., 2007; Deslauriers et al., 2011, 2019; Freeman et al., 2014). Additionally, research has begun to suggest that active learning, as opposed to lectures focused on delivering content, provides "disproportionate benefits for STEM [science, technology, engineering, and mathematics] students from disadvantaged backgrounds and for female students in male-dominated fields" (Freeman et al., 2014, p. 8413) and can reduce the gender performance gap (Lorenzo et al., 2006).

Conscientious instructors want to incorporate the most effective pedagogical approaches into their teaching, but this is often not a simple matter. In several exploratory studies, instructors have identified barriers to implementing active learning in their courses. Some of the challenges they identify include a lack of time to prepare activities, a lack of training in how to implement active learning efficiently and effectively, or overly large class sizes that make active learning more challenging (Michael, 2007; Shadle et al., 2017; Ungar et al., 2018; Kim et al., 2019). Shadle et al. (2017) noted other instructional challenges that presented significant barriers to implementing active learning, such as limitations of learning spaces, student expectations about college lectures, and lack of class time. The particular worry that there is not enough class time for active learning due to the amount of material that needs to be covered is a common challenge (Graffam, 2007). Yoshinobu and Jones (2012) describe this as "the coverage issue," which they define as "the set of difficulties that arise in attempting to cover a lengthy list of topics" (p. 303).

Interestingly, both faculty and students express this worry. In one study, $65 \%$ of life science educators identified "time constraints due to the need to cover content" as a major barrier to teaching science process skills to students (Coil et al., 2010). Likewise, students reported that high among the challenges to adopting active learning was a lack of class time to cover content (Michael, 2007; Miller and Metz, 2014; Tsang and Harris, 2016).

Michael (2007) notes the fear of a negative perception by colleagues as another barrier that can push faculty toward a content-coverage teaching approach. Brownell and Tanner (2012) identify the reluctance of scientists to be perceived as reflective teachers, arising from restrictive conceptions of scientific identity, as an additional factor blocking pedagogical change.

Other barriers frequently noted are more systemic. Michael (2007) describes the lack of faculty reward structures as an obstacle for faculty who wish to use active learning or other learner-centered approaches in their teaching. Bathgate et al. (2019) also noted that the perceived lack of institutional and systemic encouragement inhibited instructors from using active-learning techniques. Their results suggest that increasing faculty support could have a large impact on promoting learner-centered teaching strategies. Institutional rewards for teaching are beyond the scope of this paper, but many of the other challenges can be addressed by providing instructors with support in developing new instructional materials, ideas for the implementation of active learning, and empirical evidence showing that active-learning techniques increase learning. To help support faculty to move away from an exclusively content-coverage approach, we first need to understand why the imperative for content coverage persists.

\section{Why Do Instructors Feel the Need to Cover Content?}

We encounter many instructors who feel the obligation to cover content. But why is this the case? One possible source is the burgeoning size of textbooks. As research continues to produce more knowledge, this knowledge is incorporated into new editions of textbooks. Instructors may feel compelled to include all of these topics in their already overloaded courses and perhaps to justify the increasingly expensive textbooks. Another is the persistence of disciplinary norms, which define what good teaching looks like and what good teachers do, stemming from both faculty and students. In disciplines where lecture is common, to do something other than lecturing is a risk, particularly for pre-tenure faculty, who may feel they will be evaluated negatively for teaching outside accepted norms.

A third source is institutional, with the perceived need to cover particular content arising from a course's place in a larger curriculum. For example, if most or many students from Biol 101 go on to its successor course, Biol 102, and the material in Biol 102 builds on Biol 101's material, Biol 101 instructors frequently feel obligated to expose students to the requisite content, often in the form of a collection of facts. This dynamic may manifest itself in curricular reviews or comments from colleagues who insist that, for example, the structure of nucleotides must be covered before students begin a unit on DNA replication. Professional admissions and licensing examinations as well as accreditation processes sometimes provide a similar prescription to cover content. This is particularly true for requirements for professional programs in which accreditation dictates much of the content of a course.

Even in a single, stand-alone course, instructors can feel a duty to cover certain content that arises from their perceptions of their field's standards. For example, an instructor teaching introductory biology for nonmajors might believe that his or her students simply must not leave the course without being exposed to the stages of mitosis, which he or she must therefore cover. Even if expectations of content coverage are self-imposed, some faculty indicate that they lack the time to reevaluate their courses to make decisions about content reduction because of their busy schedules (Henderson and Dancy, 2007). 
Because the practice of content coverage has persisted, despite its reported ineffectiveness compared with active learning, the American Association for the Advancement of Science (AAAS, 2011) recommended an approach that focuses on core concepts and competencies. This was identified as part of a shared vision for undergraduate biology education in the Vision and Change report. The report suggests that instructors should "shift their focus from faculty-centered teaching to student-centered learning, and away from presenting all the facts (i.e., 'covering the material') toward clearly articulating expected student learning outcomes and following the students' progress in achieving those outcomes" (AAAS, 2011, p22). More interactive teaching strategies are recommended, but the authors acknowledge that, in implementing these strategies, "faculty cannot conceivably cover as much material, p26." By advocating for fewer concepts presented in greater depth, the AAAS has uncoupled the definition of an effective instructor from the idea of content coverage. This shift aligns with the vast body of evidence that supports active learning (Hake, 1998; Prince, 2004; Knight and Wood, 2005; Handelsman et al., 2007; Deslauriers et al., 2011, 2019; Freeman et al., 2014), but practically speaking, it means that our conception of what it means to teach well must also change.

We propose that moving instructors away from a focus on coverage requires two steps. The first is replacing the goal of coverage with the goal of student learning. Many if not all of the considerations that motivate instructors to cover content are entirely legitimate, including the need for students to "know" a collection of facts. Students do need mastery of certain factual content in order to support a complex conceptual understanding that prepares them for successor courses. Some students need adequate preparation for an admissions exam or for a professional licensure exam. Central foundational ideas in a field should be familiar to students completing certain courses. And students must certainly be given the resources, opportunities, and guidance necessary for mastering any material that is assessed. But we argue that what is most important is student learning, not what students were exposed to in a given class (DiCarlo, 2009; Weimer, 2014; Monahan, 2015; Wankat and Oreovicz, 2015). Indeed, just because a concept is mentioned or covered in class does not mean students have learned it. We list some of the attributes of a content-coverage approach in comparison to a learner-centered approach in Table 1 .

Once the shift from content coverage to student learning is made, instructors can move to the second step: understanding how students learn and which strategies best promote student learning. Much is known on this score, and the science of teach- ing and learning clearly tells us that covering content is not the best way to help one's students retain facts, core concepts, and competencies and then be able to transfer and apply their conceptual understanding to other situations (Hake, 1998; Prince, 2004; Handelsman et al., 2007; Deslauriers et al., 2011). Moreover, moving away from a focus on content coverage may promote equity in STEM education by supporting the learning of traditionally underrepresented groups of students (Lorenzo et al., 2006; Handelsman et al., 2007; Eddy and Hogan, 2014; Freeman et al., 2014).

\section{STRATEGIES TO MOVE AWAY FROM CONTENT COVERAGE AS A TEACHING APPROACH}

From our work as instructors and consulting with faculty, we recommend a three-step process to shift one's pedagogical focus away from content coverage and toward a learner-centered approach to teaching. These three steps rely on evidence-based strategies that have been deemed effective by the faculty who use them. Our experience suggests that these steps have the greatest impact when implemented together, though we believe that implementing only one or two could be beneficial for student learning. To help students understand and master content and to increase their ability to learn beyond the material that is explicitly covered, an instructor should: 1) identify the core concepts and competencies of a course; 2) create an organizing framework for the core concepts and competencies; and 3) teach students how to learn in the discipline.

\section{Identify the Core Concepts and Competencies}

A necessary first step in moving away from content coverage is to define the most important (core) concepts and competencies for students to master. We define "concepts" as knowledge in the form of ideas for which students must have a deep and lasting understanding and "competencies" as skills that students must possess to appropriately apply concepts in new situations (Table 1). These can then be used as criteria for curating the content, assessments, and activities of a course (Cooper et al., 2017). We use the word "curate" in the same sense that a museum-rather than displaying all of the pieces in its collection-curates an exhibit by choosing the work most representative of a period or style to create an "experience" for the viewer. In teaching, curating involves identifying what core concepts and competencies are at the heart of what students should learn deeply and be able to use. Identifying these will establish the course focus, to which all course content should map, allowing other less relevant content to fall away. Note that the idea of core concepts is distinct from a list of topics or book chapters.

TABLE 1. Attributes of a content-coverage approach compared with a learner-centered approach to teaching

\footnotetext{
Content-coverage approach

- Course design is guided by a list of topics, often from textbook chapters.

- Primary pedagogy is to present information on a wide variety of topics, emphasizing breadth over depth.

- Class sessions deliver content to students.

- Assessments may include anything addressed in class sessions and homework.

Learner-centered approach

- Course design is guided by instructor-chosen core concepts and competencies.

- Primary pedagogy is to focus in depth on a few chosen topics related to core concepts and competencies.

- Class sessions provide students with information and opportunities to engage with concepts and practice competencies.

- Assessments focus on concepts and competencies emphasized in the course.
} 
Core concepts are typically broader, threaded throughout much of the course, and more inclusive of analytical and reasoning skills. For example, "membrane transport" may be a topic from a textbook, whereas a related core concept might be that a molecule's movement across a cell membrane is affected by its size, biochemical properties, and the electrochemical gradient.

Wiggins and McTighe (2005) and Fink (2013) recommend the use of backward course design as a way to begin identifying core concepts and competencies in the form of learning outcomes, what students should know and be able to do at the end of a course. These outcomes drive the choice of assessments and activities for the course. Ultimately the outcomes, assessments, and activities should be in alignment, such that class activities prepare students for assessments that are designed to provide evidence of attainment of outcomes (Wiggins and McTighe, 2005; Handelsman et al., 2007; Fink, 2013).

Instructors can identify appropriate core concepts and competencies by asking themselves: "Of all of the possible ideas and skills I could include in my course, what are the most essential that students should master by the end of the course?" This requires instructors to prioritize concepts and competencies as a means to decide which material to include or eliminate. This curated collection of core concepts and competencies serves as the course curricular foundation that all concepts, competencies, and factual knowledge should map to and support. Existing and potential course content that does not support this curricular foundation can be eliminated.

Our experience as developers of teaching skill in faculty indicates that many instructors have difficulty prioritizing, because they believe all of their course material is important. Fortunately, the Vision and Change report has already identified agreed-upon core concepts and themes in biology (AAAS, 2011). These five core concepts are: 1) evolution; 2) structure and function; 3) information flow, exchange, and storage; 4) pathways and transformations of energy and matter; 5) systems. Instructors are encouraged to select from these five concepts the one(s) most suitable as a basis for teaching each course. Core concepts have similarly been identified for undergraduate chemistry (Murphy et al., 2012; Cooper et al., 2017), genetics (Smith and Wood, 2016), and physiology (Michael et al., 2017).

Likewise, the Vision and Change report identifies six core competencies, defined as relevant skills that students need to develop in order to apply core concepts. These include the ability to 1 ) apply the process of science; 2) use quantitative reasoning; 3) use modeling and simulation; 4) tap into the interdisciplinary nature of science; 5) communicate and collaborate with other disciplines; and 6) understand the relationship between science and society. Together, these core concepts and competencies in the Vision and Change report represent what an undergraduate biology major should know and be able to do upon completion of the curriculum-not in the course of one semester (AAAS, 2011). In other words, the Vision and Change report fully acknowledges that a single course cannot effectively address all of these core concepts and competencies.

Brownell et al. (2014) have provided examples of applications of these core concepts and competencies appropriate for three major subdisciplines of biology, each of which exemplifies the core concepts and competencies in ways specific to the subject: 1) molecular, cellular, and developmental biology; 2) physiology; and 3) ecology and evolutionary biology. For example, an ecology course may look at systems by examining the ways that species' abundance and distribution are limited by the available resources. A physiology course may study systems by focusing on the impact an "alteration of a single gene or molecule in a signaling network may have at the cell, tissue, or whole-organism level" (Brownell et al., 2014, p. 208). Selected core concepts can then become a central course theme, question, or problem and can help guide the selection of key course examples. Individual examples are introduced and discussed within the context of the system within which they function. In the ecology class, examples may reflect the impact of climate change on different plants and animals within an ecosystem. In the physiology class, increased susceptibility to certain cancers may reflect the impact of genetic mutations in key growth factor genes.

The identification of core concepts anchors students in the "big picture" while they are swimming in a sea of details. Content that consists of a series of unconnected facts can be overwhelming, and many students accommodate this challenge by turning to rote memorization, thus never integrating those facts in a way that will allow them to retrieve and apply the material in the future. Identifying core concepts and relating course materials to those ideas will make it easier for students to transfer knowledge and apply it later on (Connell et al., 2016; Cooper et al., 2017).

Identifying core competencies allows an instructor to offer more opportunities for students to practice and receive feedback and better develop skills. As an example, one of the authors (C.L.N.) uses the core concept "structure function" to shape her physiology and pathophysiology courses. The specific competency she wants her students to practice and learn is to "predict how changes in structure lead to changes in function." Throughout the course, students practice predicting how changes in various physical structures (due to genetics, environment, or injury) result in changes to that structure's function, whether of cells, tissues, organs, organ systems, or ultimately the entire organism. This competency aligns with "applying the process of science," the first competency listed in the Vision and Change report (AAAS, 2011). To assess this competency, students are asked questions such as, "If there is a mutation that affects the structure of hemoglobin in the blood so that it binds oxygen less efficiently, what happens to the body's ability to take up oxygen? What organismal signs and symptoms would you expect?"

Making these kinds of predictions requires not only familiarity with the relationship between structure and function of a molecule, cell, tissue, or organ, but also an understanding of how that element functions within a larger system. It is precisely this kind of competency that is difficult to acquire through an exclusively content-coverage approach but can be readily practiced and learned through learner-centered teaching techniques (Thompson et al., 2003). In this way, students can apply their factual knowledge and their understanding of the logical order of a process or system to make informed predictions about changes in that system. With this core competency as a guide, the instructor can focus on a few key examples to illustrate it and avoid covering all of the possible molecules, cells, tissues, organs, and systems that contribute to a disease state. Students can then be taught how to apply this competency to the consideration of molecules and systems that were not discussed in the class. 
In focusing a course on core concepts and competencies, the instructor moves away from the goal of covering a breadth of material in a shallow manner to having students engage with a subset of material in more depth. Some instructors may fear that student performance on formal assessments will be negatively impacted by gaps in their factual knowledge. However, studies indicate that this approach focusing on depth shows no decrease in performance, but rather an improvement in many cases (Schwartz et al., 2009; Luckie et al., 2012; Kogan and Laursen, 2014; Connell et al., 2016). Luckie et al. (2012) have shown in an introductory college biology laboratory course that reducing the amount of factual content while providing students with a thorough understanding of the remaining content through increased inquiry learning resulted in improved performance on standardized exams, even when the exams included questions on content that had not been covered in class. Connell et al. (2016) refer to a similar approach in a large-enrollment biology course as "content unburdening." They show that "paring content down to specific learning targets" (p. 13) resulted in improved student learning (Connell et al., 2016). In math courses, Kogan and Laursen (2014) reported that students who participated in inquiry-based learning sections, where less material was covered than in traditionally taught sections, displayed no negative effects on performance in later math courses and, in some cases, outperformed students from the traditional sections. A study by Schwartz et al. (2009) has shown that better student performance in introductory college science courses (biology, chemistry, and physics) is associated with participation in high school science courses (biology, chemistry, and physics) that address a few core topics in depth rather than many topics. Additionally, they found that decreased student performance in introductory college biology courses correlates with participation in high school courses that focus on covering a breadth of material.

In the following sections, we describe three different strategies for identifying the key core concepts, competencies, and discipline-specific habits of mind that students should take away from a course, while reducing content that does not directly support those goals: 1) identify the ideal course outcome and connect the course material to it; 2) identify what is relevant to students' lives; and 3) identify the exemplars (representative examples) for a category in your field. One, two, or all three strategies could be used to define priorities to curate course content. They share the common goal of a focus on student learning rather than on covering content.

Identify the Ideal Course Outcome and Connect the Course Material to It. To identify the ideal course outcome for students in your course, Fink (2013) recommends asking "When the course is over and it is now one or two years later, what would you like to be true about students who have participated in your course that is not true of others?" (p. 9). Other questions to ask include: "What key information, ideas, or perspectives are important for students to understand?," "What important competencies do students need to develop?," "What connections among ideas should students recognize and make?," and "What are the big questions in your field?" (Bain, 2004; Wiggins and McTighe, 2005). These core ideas are also shaped by such situational factors of a course (Fink, 2013) as preparing students for the next course in a series or meeting the required depart- ment, college, or institutional standards. For instance, a physiology class may have as its ideal outcome that students learn that structure determines function, whether dealing with organs and organ systems or molecules and cells. According to Fink (2013), identifying an overall ideal course outcome provides the direction and scope to shape the entire course. Identifying core course concepts has been a foundational strategy for curricular design in the work of the authors. Feedback we have collected over the years from workshops, seminars, and individual faculty consultations indicates that instructors find this practice a useful way to determine course priorities and an aid in the identification of appropriate assessments and class activities aligned with those priorities.

Identify What Is Relevant to Students' Lives. Relevance could relate to the next course in a series, application to a professional school, or students' lives as members of society beyond your course (Chamany et al., 2008). To help identify these, ask yourself, "What timely subjects in the media could I link to course content? Can I identify examples that directly relate to the health and well-being of students or their families?" The goal is to develop enduring understanding of core concepts by motivating student interest in them. One way to accomplish this is to explain to students why your core concepts are relevant to them. For example, the transformation of energy and matter in the form of plant photosynthesis can be made relevant to students by pointing out that this process is the most important source of oxygen in our atmosphere. In one introductory biology course, student teams work on a genetic engineering proposal to address a societal problem of their choosing, which is then presented at an end-of-term poster session. Throughout the term, course material is related to required components of the poster, which include addressing societal need and the ethical considerations of the proposed project. The quality of the final products provides the instructors with evidence of the effectiveness of this approach (Wick et al., 2013). Feedback from instructors who have successfully developed their course content around themes relevant to students' lives have reported that it also helps them better focus and integrate their course material with their assessments and classroom activities. Institutions with programs that highlight the relevance of biology to students' everyday lives have seen increases in STEM graduation rates (Chamany et al., 2008).

Identify the Exemplars for a Category in Your Field. An exemplar is a representative example chosen from a broader collection of possible examples to highlight key distinguishing features. For instance, in a genetics course, among all known mutations that lead to disease, two or three could be chosen to act as exemplars. Focusing on these exemplars rather than the full range of diseases and conditions is part of a strategy to develop deep conceptual understanding using these critical examples as a means to facilitate comparison and categorization of new examples. Students can use the exemplar condition to compare and contrast with other conditions (Bordage, 2007). For instance, a genetics class could focus on sickle cell anemia, Down syndrome, and hereditary breast cancer to serve as exemplars of disease states caused by a point mutation leading to a single amino acid change in a protein, an error in meiosis leading to the presence of an extra chromosome, and a combination 
of a genetic change and environmental effects, respectively (Mukerjee, 2016; Simonds et al., 2016). These exemplars can help students to develop conceptual understandings of mutation, gene expression, and cancer that can provide frameworks to categorize and compare and contrast other genetic disorders.

\section{Create an Organizing Framework for the Core Concepts and Competencies}

After identifying core concepts and competencies to help curate course material, an instructor should develop an organizing framework for the material to help students learn in a way that aids in long-term retention. Visual graphic and semantic organizers have been shown to positively influence cognitive processing and improve student learning (Brown, 2014; McCrudden and Rapp, 2017; Colliot and Jamet, 2018). By focusing on organizing core concepts into a framework, we are not suggesting that facts no longer need to be learned, or even memorized; indeed, students must have a foundation of basic knowledge to draw upon in order to work with and apply the core concepts and competencies. We are suggesting, rather, that students must also understand that basic knowledge and facts fit into a larger framework of interconnected principles or ideas that can be used to provide them with context.

As experts, instructors typically have a clear sense of how various parts of a course fit together and how these elements fit into a larger structure within the discipline. Experts also use general models or frameworks to organize and make sense of the content in their disciplines and to integrate new knowledge from research into those models. As novices to the discipline, students necessarily lack these structures. Intentionally providing a visual representation of an organizing framework that indicates how the core concepts and competencies fit together can help students to better organize and connect their learning (Ambrose et al., 2010; Brown, 2014; McCrudden and Rapp, 2017).

Development and use of a course-organizing framework helps students incorporate new information, and transfer prior learning and skills to new situations. Such a framework not only provides students with a tool to manage the learning of new material within the overall conceptual structure of the course and subject, but also helps students think like professional biologists who use models and frameworks. New topics no longer stand alone as silos of information to memorize but rather become part of an interconnected web of information that maps to core ideas (National Research Council, 2001; Cooper et al., 2017). The use of instructor-created visual organizing frameworks has been shown to improve students' learning (Colliot and Jamet, 2018). A course-organizing framework could take a number of forms (Eppler, 2006; Ambrose et al., 2010; Murphy et al., 2012; Cooper et al., 2017; Michael et al., 2017), some of which are described in the following sections.

Biological Relationships or Cycles. A visual image can serve as an organizing framework that shows how the major themes of the course are interrelated (Eppler, 2006). For instance, one of the core concepts identified for physiology is homeostasis (the ability of an organism to maintain a relatively stable internal environment in the face of a changing external environment and varying internal activity; McFarland et al., 2016). Figure 1A is a visual organizing framework representing the key common elements of a physiological cycle adapted from Modell et al. (2015) to support learning of neural regulatory homeostasis. Figure 1B shows a sample framework illustrating regulation of arterial $\mathrm{CO}_{2}$, but it can also be applied to many homeostatic processes in multiple different systems within an organism. For example, students can focus on sensors when learning about somatic and special senses, the afferent pathway when learning about sensory nerves, the control center when learning about the central nervous system, the efferent pathway when learning about somatic and autonomic motor nerves, and the effectors when learning about muscles and glands. By referring to this figure when studying various aspects of anatomy and physiology, students no longer see regulation of each individual organ system as a stand-alone topic to memorize but understand that common homeostatic mechanisms underlie them all. One of us (C.L.N.) uses a similar reflex-response framework in her physiology and pathophysiology classes, and student feedback indicates this concept framework is helpful for their learning in the course.

Biological Hierarchies and Pathways. An organizing framework can also represent the concept of biological hierarchies and pathways related to core concepts, as shown in Figure 2. This diagram is an organizing framework for a pharmacology course focusing on the synapse. This framework indicates that synapses associated with different types of neurotransmitters share many common processes that contribute to neuronal signaling pathways that are part of larger hierarchical biological systems. For example, in a unit on dopamine synapses, a drug that increases dopamine release and a drug that activates postsynaptic dopamine receptors might be predicted to have similar effects at the synapse level, in neural signaling pathways, and in a patient with Parkinson's disease. Organizing information in this way enables students to predict the effect of drug interaction on synaptic output rather than simply memorizing a long list of drugs and drug targets that may soon be forgotten after the course is over.

Faculty with whom we have worked who use organizing frameworks to illustrate hierarchies and pathways have shared that the use of such frameworks helped students connect core concepts and competencies in meaningful ways. An additional benefit that has been shared with us is that the creation of these frameworks helps instructors make decisions about assessments and activities to use in their courses.

Narrative. Another type of organizing framework can take the form of a narrative arc or story related to the core ideas of course material, perhaps beginning with a central question in the field. Throughout the course, students can be brought back to this primary question, reminded of the value or interest in discovering the answer to that question, and asked to update the current answer based on the material of the course so far and then to refine the question for the next portion of the course. For example, the primary question of a particular global health and ecology class is "How can we feed the world without destroying it?" Meaning, how can the human population be fed without destroying global natural environments? The course material is framed as possible answers to the question as students explore global food insecurities and methods of addressing 


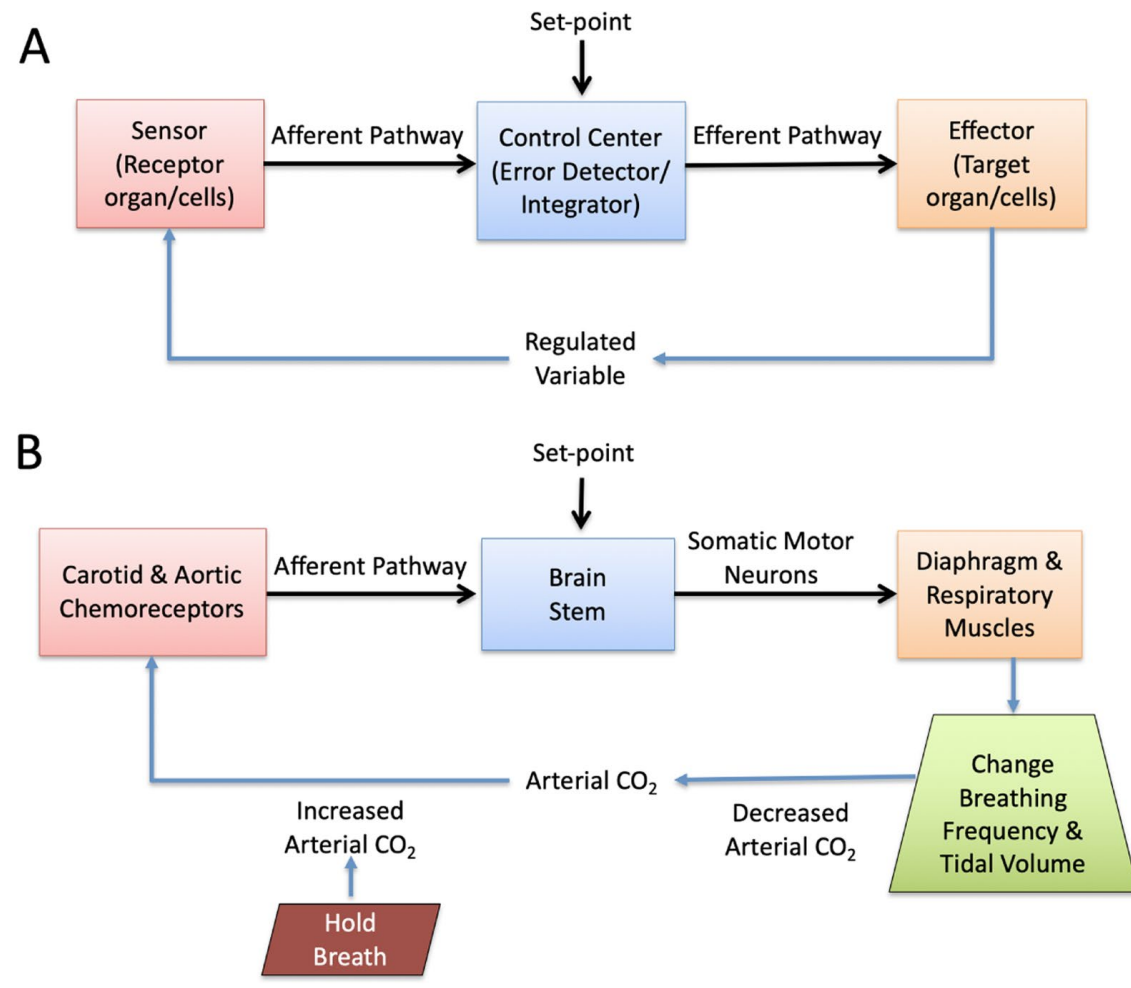

FIGURE 1. (A) This is a simplified visual representation of organismal neural regulatory homeostasis adapted from Modell et al. (2015) and can be used as an organizing framework for teaching physiology. The key common elements of homeostasis are included. Here, a sensor is a structure that includes a sensory receptor that monitors the internal environment and sends information to a control center (aka "integrator"). When the regulated variable moves away from its set point, the control center sends a signal to an effector(s) that returns the regulated variable to its set point. This simplified framework can be modified to describe homeostatic processes in multiple different systems within an organism. (B) An example of application of the framework to a specific regulated variable: arterial $\mathrm{CO}_{2}$. Arterial $\mathrm{CO}_{2}$ will increase when a subject holds his or her breath. This is measured by sensors, which in this case are carotid and aortic chemoreceptors. The control center (the brainstem) receives this message and sends a message to the effectors (the diaphragm and respiratory muscles) to increase breathing frequency, thus returning the regulated variable (arterial $\mathrm{CO}_{2}$ ) to its normal set point.

them, along with the environmental impacts of various agricultural and livestock practices. In this way, students understand that there is no one right answer to the question and that evaluating different options will require considering both aspects of the question. We have seen this work well in courses with big picture problem-solving approaches that require viewing from multiple angles. As mentioned previously, a central question with high relevance to students' lives can also help increase student motivation.

Using an Organizing Framework. Regardless of its form, once an organizing framework has been developed there are various ways it can be used to promote student learning. A framework can be used as:

- an advance organizer given at the beginning of each week or class session to indicate how the content or skills being taught fit into the broader framework of the course as a whole;
- an outline for a class session or unit referenced periodically to show which relationships are being explored at different points in the unit;

- a review tool at the end of a class session or unit to summarize what was discussed; and/or

- a study guide for students to organize course material when preparing for assessments.

However you choose to use an organizing framework, we have found that it is important to provide students with instruction on how they can use the framework to aid their learning during a course.

\section{Teach Students How to Learn in Your Discipline}

A third crucial aspect of changing one's course (after curating the content to focus on core concepts and competencies and creating an organizing framework) is helping students develop the skills they need to monitor and direct their learning in your discipline. Teaching students "how to learn" allows them to continue to appropriately assimilate new information, including material that was not explicitly mentioned in class. These lifelong learning skills allow students to transfer course core concepts to new situations (Ambrose et al., 2010). Learning how to learn also provides students with the ability to incorporate new competencies into an existing organizing framework as they progress in their studies after your course is over.

Learning how to learn is a broad category that encompasses different levels of student responsibility for their learning. This includes providing students with the skills they need to locate and evaluate credible resources such as primary research articles and publicly available data repositories. One approach is simply sharing the periodical databases and search terms you use for finding information on an unfamiliar topic. Developing this skill allows students to gather information independently from you and from the course texts.

Learning how to learn also includes teaching students metacognitive strategies that ask them to be aware of and analyze how they learn. While encompassing many information- processing activities, metacognition is understood to consist of "reflecting on and directing one's own thinking" (Ambrose et al., 2010, p. 190). Explicitly drawing attention to the importance of metacognition is a good way to help students become aware of their own learning process. Students who use metacognitive strategies improve their learning efficiency, both in and beyond the classroom setting, while increasing their ability to learn independently (Hacker et al., 2009; Ambrose et al., 2010; Luckie et al., 2012; Cook et al., 2013; Wilson and Conyers, 2016). 


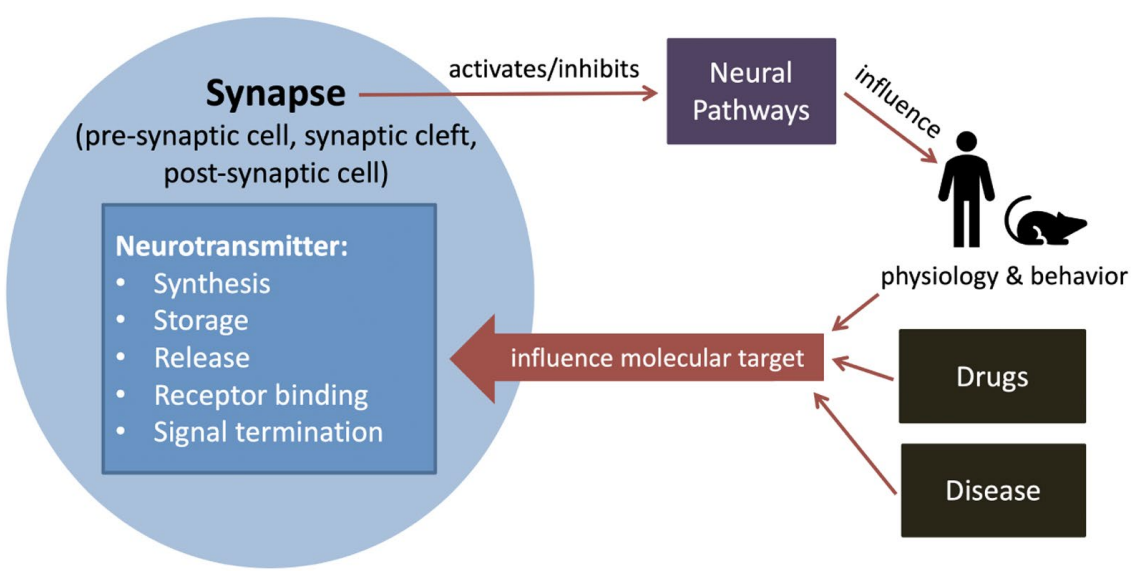

FIGURE 2. This visual framework is for a Pharmacology of the Synapse course designed to show the effects of drug binding on different synaptic processes. This figure emphasizes that: 1) synapses share many common neurotransmitter-related processes with which drugs can interact and 2) changes in those processes contribute to neural pathways that are part of larger hierarchical biological systems. The central circle ("Synapse") represents the physical structure of a generic synapse, which comprises a presynaptic neuron, a postsynaptic neuron or other cell type, and the synaptic cleft, the space between them. The square within the synapse represents the common neurotransmitter-related processes of synthesis, storage, release, receptor binding, and signal termination that are shared by different synapse types. The upper rectangle ("Neural Pathways") indicates different biological hierarchical levels at which synapses influence the physiology and behavior of organisms. The lower rectangular boxes ("Drugs" and "Disease") indicate that drugs and disease affect neurotransmitter processes by interacting with different molecular targets within the synapse, thus modifying (activating or inhibiting) synaptic output. This framework helps learners in this course classify and organize information about how drugs affect neurotransmitter processes, synapses, and hierarchical levels from pathways to organisms.

Instructors can choose the types of learning skills appropriate for their material and course objectives. We discuss in the following sections some approaches you can use to help students learn how to learn. You could incorporate any or all of these into your course.

Make Learning How to Learn Part of Your Curriculum. By informing students that one of your goals for them is to learn how to learn in your discipline, you demonstrate that you value this as an important competency. Explicitly teaching students how to learn is part of the process of training students to think like a biologist (Tanner, 2012; Couch et al., 2015). You could create an assignment asking students to evaluate a number of different sources based on a set of criteria that you provide. This helps students develop the competencies to evaluate sources of information so that they can make informed decisions about new resources. You can discuss and recommend evidence-based study approaches, such as self-testing, spaced practice, interleaved practice (students mix or interleave multiple topics when they study), and elaborative rehearsal (students make an association between the new information being learned with what they already know; Cook et al., 2013; Dunlosky et al., 2013; McGuire, 2015). These approaches would help students learn and better retain what they have learned. McGuire (2015) outlines an approach to guide this discussion with students that can be easily adapted for biology courses. After exams and quizzes, you can ask students to actively reflect on the effectiveness of their study habits (Couch et al., 2015) through the use of exam wrappers and guiding questions (Ambrose et al., 2010; Tanner, 2012). All of these activities are designed to help student performance in your course, but also in future biology courses and beyond. Luckie et al. (2012) approached incorporating learning how to learn in a biology course by reducing course content and replacing it with explicit opportunities to develop competencies related to learning and found that students achieved better learning outcomes.

Model Your Own Metacognitive Practices. A challenge for instructors is that, as experts, we have a clear sense of how the elements of a course fit together and into the discipline, but it can be difficult for us to recall what it was like to think like a novice. This is sometimes referred to as "expert blind spot" (Wiggins and McTighe, 2005; Ambrose et al., 2010). Expert blind spot may position an instructor to not notice areas where students get confused. One way to address expert blind spot is to make explicit your own approaches to solving challenges that students are likely to encounter during their studies (Tanner, 2012). "Thinking aloud" is an approach instructors can use to model expert cognitive skills. When instructors articulate their thinking process to students in response to a question, procedure, case, issue, or problem, they model critical-thinking and problem-solving skills. Students can practice similar thought processes with partially worked examples and different cases in new situations, while being provided with feedback on their efforts. For instance, what steps (and in which order) would you, the expert, take to classify an unknown plant species (Thyagharajan and Raji, 2018)? Likewise, if an instructor does not know the answer to a student's question, he or she could list Internet search terms that could be used to find related information. The instructor could also have students use their personal electronic devices in class to search with these terms or ask for their own terms and then have a discussion about which search terms provided the best resources. The use of an organizing framework, described earlier, is another way in which instructors can make their cognitive skills explicit. Evidence we have gathered from student feedback on instructor strengths indicates that many students appreciate how their instructors walk them through how to approach a problem or point out areas in the process where it is easy to get lost or confused.

Have Students Focus on the Problem-Solving Process, rather than Just the Correct Answer. An important aspect of biology education is to learn how to design approaches to address questions and hypotheses. Teach students the basic elements of experimental design, including the use of 
negative and positive controls, instrument calibration, and the use of standard curves. As in think-aloud exercises, students can answer questions and solve problems using self-explanations (the process of describing thinking and decision making) individually or with peers. When discussing experimental approaches described in the literature, students can be asked whether other ways of proceeding could address the same question. Ask students what approach could be used to address unanswered questions in the field. This helps build a general organizational pattern of the experimental approach, which helps novices form a foundation of understanding that leads toward expertise and mastery (Tanner, 2012; Hoskinson et al., 2013). These teaching approaches also provide students with experience in applying the scientific process, which is a core competency proposed in Vision and Change (AAAS, 2011).

For example, in the introductory biology course in which student teams work on genetic engineering proposals, the students do not actually perform the genetic manipulations. Rather, they describe the need for the project and propose how the genetic manipulations would be done, including the proposed gene editing and transgenic organism selection and screening processes (Wick et al., 2013).

\section{CONCLUSION}

In this paper, we have focused on the idea of content coverage as a barrier to incorporating evidence-based, learner-centered approaches to teaching. We have described the history of content coverage as a teaching approach and the barriers to moving away from content coverage. We have proposed a threestep process that will help faculty switch from a default teaching goal of covering content to a learner-centered approach focused on core concepts and competencies that students need to learn. We encourage instructors to view content as a collection of concepts, competencies, and facts to be deliberately selected rather than a list of topics to be covered. By situating core concepts and competencies within an organizing framework and teaching students how to learn in their disciplines, faculty can organize material in ways more compatible with active learning and other evidence-based teaching approaches.

Although adoption of these strategies will not remove all of the barriers related to content coverage (e.g., faculty incentives, disciplinary teaching norms), we believe that these strategies represent important steps that must be taken for effective change. The instructors with whom we work often describe a feeling of relief when they recognize the advantages of moving away from covering a breadth of content and moving toward curating content so students can learn more deeply. In this way, instructors can be freed from the tyranny of content coverage to teach with strategies that result in deeper and longer-lasting learning for all students.

\section{ACKNOWLEDGMENTS}

The authors would like to thank Maire Sustaceck, Kate Martin, David Matthes, Abdi Warfa, and Brian Gibbens for careful reading and insightful comments on the manuscript drafts; James Ondrey for assistance with the figures; and Ilene Alexander for discussion on the initial ideas for the manuscript. We also want to thank the editor and two anonymous reviewers for their detailed feedback and suggestions.

\section{REFERENCES}

Ambrose, S. A., Bridges, M. W., DiPietro, M., Lovett, M. C., \& Norman, M. K (2010). How learning works. San Francisco, CA: Jossey-Bass.

American Association for the Advancement of Science. (2011). Vision and change: A call to action, Final report. Washington, DC.

Bain, K. (2004). What the best college teachers do. Cambridge MA: Harvard University Press.

Barr, R. B., \& Tagg, J. (1995). From teaching to learning-A new paradigm for undergraduate education. Change, 27(6), 18-25.

Bathgate, M. E., Aragon, O. R., Cavanagh, A. J., Frederick, J., \& Graham, M. J. (2019). Supports: A key factor in faculty implementation of evidence-based teaching. CBE-Life Sciences Education, 18(2), ar22.

Bordage, G. (2007). Prototypes and semantic qualifiers: From past to present Medical Education, 41(12), 1117-1121.

Brown, S. (2014). The doodle revolution. New York: Penguin

Brownell, S. E., Freeman, S., Wenderoth, M. P., \& Crowe, A. J. (2014). BioCore guide: A tool for interpreting the core concepts of vision and change for biology majors. CBE-Life Sciences Education, 13(2), 200-211.

Brownell, S. E., \& Tanner, K. D. (2012). Barriers to faculty pedagogical change: Lack of training, time, incentives, and... tensions with professional identity? CBE-Life Sciences Education, 11(4), 339-346.

Chamany, K., Allen, D., \& Tanner, K. (2008). Making biology learning relevant to students: Integrating people, history, and context into college biology teaching. CBE-Life Sciences Education, 7(3), 267-278.

Coil, D., Wenderoth, M. P., Cunningham, M., \& Dirks, C. (2010). Teaching the process of science: Faculty perceptions and an effective methodology. CBE-Life Sciences Education, 9(4), 524-535. 10.1187/cbe.1001-0005

Colliot, T., \& Jamet, E. (2018). Does self-generating a graphic organizer while reading improve students' learning? Computers \& Education, 126, $13-22$.

Connell, G. L., Donovan, D. A., \& Chambers, T. G. (2016). Increasing the use of student-centered pedagogies from moderate to high improves student learning and attitudes about biology. CBE-Life Sciences Education, 15(1), ar3.

Cook, E., Kennedy, E., \& McGuire, S. Y. (2013). Effect of teaching metacognitive learning strategies on performance in general chemistry courses. Journal of Chemical Education, 90, 961-967.

Cooper, M. M., Posey, L. A., \& Underwood, S. M. (2017). Core ideas and topics: Building up or drilling down? Journal of Chemical Education, 94(12), 541-548.

Couch, B. A., Brown, T. L., Schelpat, T. J., Graham, M. J., \& Knight, J. K. (2015) Scientific teaching: Defining a taxonomy of observable practices. $C B E-$ Life Sciences Education, 14(1), ar9.

Deslauriers, L., McCarty, L. S., Miller, K., Callaghan, K., \& Kestin, G. (2019) Measuring actual learning versus feeling of learning in response to being actively engaged in the classroom. Proceedings of the National Academy of Sciences USA, 116(39), 19251-19257. doi: 10.1073/pnas.1821936116

Deslauriers, L., Schelew, E., \& Wieman, C. (2011). Improved learning in a large-enrollment physics class. Science, 332(6031), 862-864.

DiCarlo, S. E. (2009). Too much content, not enough thinking, and too little FUN! Advances in Physiology Education, 33(4), 257-264

Dunlosky, J., Rawson, K. A., Marsh, E. J., Mitchell, N. J., \& Willingham, D. T. (2013). Improving students' learning with effective learning techniques: Promising directions from cognitive and educational psychology. Psychological Science in the Public Interest, 14(1), 4-58.

Eddy, S. L., \& Hogan, K. A. (2014). Getting under the hood: How and for whom does increasing course structure work? CBE-Life Sciences Education, 13(3), 453-468.

Eppler, M. J. (2006). A comparison between concept maps, mind maps, conceptual diagrams, and visual metaphors as complementary tools for knowledge construction and sharing. Information Visualization, 5(3), 202-210.

Fink, L. D. (2013). Creating significant learning experiences. An integrated approach to designing college courses. San Francisco, CA: Jossey-Bass.

Freeman, S., Eddy, S. L., McDonough, M., Smith, M. K., Okoroafor, N., Jordt H., \& Wenderoth, M. P. (2014). Active learning increases student performance in science, engineering, and mathematics. Proceedings of the National Academy of Sciences USA, 111(23), 8410-8415. 
Friesen, N. (2011). The lecture as a transmedial pedagogical form: A historical analysis. Educational Researcher, 40(3), 95-102.

Graffam, B. (2007). Active learning in medical education: Strategies for beginning implementation. Medical Teacher, 29(1), 38-42.

Hacker, D. J., Dunlosky, J., \& Graesser, A. C. (Eds.). (2009). Handbook of metacognition in education. New York: Routledge.

Hake, R. R. (1998). Interactive-engagement versus traditional methods: A six-thousand-student survey of mechanics test data for introductory physics courses. American Journal of Physics, 66(1), 64-74.

Handelsman, J., Miller, S., \& Pfund, C. (2007). Scientific teaching. New York: Freeman.

Henderson, C., \& Dancy, M. (2007). Barriers to the use of research-based instructional strategies: The influence of both individual and situational characteristics. Physics Review Special Topics-Physics Education Research, 3, 020102-1-020102-14.

Hoskinson, A.-M., Caballero, M. D., \& Knight, J. K. (2013). How can we improve problem solving in undergraduate biology? Applying lessons from 30 years of physics education research. CBE-Life Sciences Education, 12(2), 153-161.

Kim, A. M., Speed, C. J., \& Macaulay, J. O. (2019). Barriers and strategies: Implementing active learning in biomedical science lectures. Biochemistry and Molecular Biology Education, 47(1), 29-40.

Knight, J. K., \& Wood, W. B. (2005). Teaching more by lecturing less. Cell Biology Education, 4(4), 298-310. doi: 10.1187/05-06-0082

Kogan, M., \& Laursen, S. L. (2014). Assessing long-term effects of inquiry-based learning: A case study from college mathematics. Innovative Higher Education, 39(3), 183-199.

Lorenzo, M., Crouch, C. H., \& Mazur, E. (2006). Reducing the gender gap in the physics classroom. American Journal of Physics, 74(2), 118-122.

Luckie, D. B., Aubry, J. R., Marengo, B. J., Rivkin, A. M., Foos, L. A., \& Maleszewski, J. J. (2012). Less teaching, more learning: 10-yr study supports increasing student learning through less coverage and more inquiry. Advances in Physiology Education, 36(4), 325-335.

McCrudden, M. T., \& Rapp, D. N. (2017). How visual displays affect cognitive processing. Educational Psychology Review, 29(3), 623-639.

McFarland, J., Wenderoth, M. P., Michael, J., Cliff, W., Wright, A., \& Modell, H. (2016). A conceptual framework for homeostasis: Development and validation. Advances in Physiology Education, 40(2), 213-222.

McGuire, S. Y. (2015). Teach students how to learn. Sterling, VA: Stylus.

Michael, J. (2007). Faculty perceptions about barriers to active learning. College Teaching, 55(2), 42-47.

Michael, J., Cliff, W., McFarland, J., Modell, H., \& Wright, A. (2017). The core concepts of physiology. New York: Springer.

Miller, C. J., \& Metz, M. J. (2014). A comparison of professional-level faculty and student perceptions of active learning: Its current use, effectiveness, and barriers. Advances in Physiology Education, 38(3), 246-252.

Modell, H., Cliff, W., Michael, J., McFarland, J., Wenderoth, M. P., \& Wright, A (2015). A physiologist's view of homeostasis. Advances in Physiology Education, 39(4), 259-266.

Monahan, N. (2015, October 12). More content doesn't equal more learning Faculty Focus, n.p.
Mukerjee, S. (2016). The gene: An intimate history. New York: Scribner.

Murphy, K., Holme, T., Zenisky, A., Caruthers, H., \& Knaus, K. (2012). Building the ACS Exams anchoring concept content map for undergraduate chemistry. Journal of Chemical Education, 89(6), 715-720.

National Research Council. (2001). Knowing what students know: The science and design of educational assessment. Washington, DC: National Academies Press.

Prince, M. (2004). Does active learning work? A review of the research. Journal of Engineering Education, 93(3), 223-231.

Schwartz, M. S., Sadler, P. M., Sonnert, G., \& Tai, R. H. (2009). Depth versus breadth: How content coverage in high school science courses relates to later success in college science coursework. Science Education, 93(5), $798-826$.

Shadle, S. E., Marker, A., \& Earl, B. (2017). Faculty drivers and barriers: Laying the groundwork for undergraduate STEM education reform in academic departments. International Journal of STEM Education, 4(1), 8.

Simonds, N. I., Ghazarian, A. A., Pimentel, C. B., Schully, S. D., Ellison, G. L., Billanders, E. M., \& Mechanic, L. E. (2016). Review of the gene-environment interaction literature in cancer: What do we know? Genetic Epidemiology, 40(5), 356-365.

Smith, M. K., \& Wood, W. B. (2016). Teaching genetics: Past, present, and future. Genetics, 204(1), 5-10.

Tanner, K. D. (2012). Promoting student metacognition. CBE-Life Sciences Education, 11(2), 113-120.

Thompson, J., Licklider, B., \& Jungst, S. (2003). Learner-centered teaching: Postsecondary strategies that promote "thinking like a professional." Theory into Practice, 42(2), 133-141.

Thyagharajan, K. K., \& Raji, I. K. (2018). A review of visual descriptors and classification techniques used in leaf species identification. Archives of Computational Methods in Engineering, 26, 933-960. https://doi .org/10.1007/s11831-018-9266-3

Tsang, A., \& Harris, D. M. (2016). Faculty and second-year medical student perceptions of active learning in an integrated curriculum. Advances in Physiology Education, 40(4), 446-453.

Ungar, O., Margaliot, A., Grobgeld, E., \& Leshem, B. (2018). Faculty use of the active learning classroom: Barriers and facilitators. Journal of Information Technology Education: Research, 17(1), 485-504.

Wankat, P. C., \& Oreovicz, F. S. (2015). Teaching engineering. West Lafayette, IN: Purdue University Press.

Weimer, M. (2014). Diversifying the role course content plays. Faculty Focus. Retrieved June 20, 2017, from www.facultyfocus.com/articles/teaching -professor-blog/course-content-can-fulfill-multiple-roles/

Wick, S., Decker, M., Matthes, D., \& Wright, R. (2013). Students propose genetic solutions to societal problems. Science, 341(6153), 1467-1468.

Wiggins, G. P., \& McTighe, J. (2005). Understanding by design (2nd ed.). Alexandria, VA: Association for Supervision and Curriculum Development.

Wilson, D., \& Conyers, M. (2016). Teaching students to drive their brains: Metacognitive strategies, activities, and lesson ideas. Alexandria, VA: Association for Supervision and Curriculum Development.

Yoshinobu, S., \& Jones, M. G. (2012). The coverage issue. PRIMUS, 22(4), $303-316$. 